\title{
Abdominal wall endometriosis: accuracy of the diagnostic triad
}

\section{Latha Lakshmi*, Vaibhav Londhe, Tejovathy K, Lily Varghese, Visali J, Aruna Kekre N}

Department of Obstetrics and Gynaecology, Christian Medical College and Hospital, Vellore, Tamil Nadu, India

Received: 05 August 2015

Revised: 19 August 2015

Accepted: 21 August 2015

\section{*Correspondence:}

Dr. Latha Lakshmi K,

E-mail: lathalakshmi30dec@gmail.com

Copyright: () the author(s), publisher and licensee Medip Academy. This is an open-access article distributed under the terms of the Creative Commons Attribution Non-Commercial License, which permits unrestricted non-commercial use, distribution, and reproduction in any medium, provided the original work is properly cited.

\section{ABSTRACT}

Background: Endometriosis is the presence of endometrial glands and stroma outside the uterine cavity and musculature. The objectives were to study the prevalence, the clinic-pathological presentation and the accuracy of the criteria for diagnosis of abdominal wall endometriosis.

Methods: This is a retrospective observational study done at a tertiary hospital. The study was approved by the ethics committee and the IRB. Data was retrieved from computer generated medical records. Specificity, sensitivity and likelihood ratio along with univariate and multivariable penalized logistic regression analysis of each presenting symptom were done.

Results: Of the 493 cases with genital endometriosis, 45 cases had AWE diagnosed clinically giving a prevalence of $8.3 \%$. Histological diagnosis of AWE was made in 41 , while 4 had suture granuloma. Pain, swelling and previous LSCS had sensitivity of $71 \%$, specificity of $100 \%$ and the likelihood ratio was 0.29 . The presentation was within 6 years after the index surgery of Caesarean section, with the odds ratio of having endometriosis of 19 (95\% CI 1.71595 ) and the $P$ value of 0.016 .

Conclusions: The diagnostic triad of previous caesarian section with swelling and pain at the scar site should prompt the possibility of AWE. However, previous LSCS was the only factor that contributed to the presence of abdominal wall endometriosis.

Keywords: Endometriosis, Abdominal wall endometriosis, Previous LSCS, Surgical excision

\section{INTRODUCTION}

Endometriosis affects $10 \%-15 \%$ of women in the reproductive age group. ${ }^{1}$ It is defined as the presence of endometrial glands and stroma outside the uterine cavity and musculature. ${ }^{2}$ Extra genital endometriosis is defined as the presence of endometrial tissue outside the pelvis, frequently involving the peritoneum, ovaries, pouch of Douglas and uterosacral ligaments. ${ }^{3}$

Abdominal wall endometriosis also called as cutaneous endometriosis, is defined as the presence of endometrial tissue within the abdominal wall superficial to the peritoneum. It affects $<1 \%$ of cases. ${ }^{4}$ Abdominal wall endometriosis develops at the site of previous abdominal operation or pelvic procedures most common being caesarean section or hysterotomy. It has also been reported at laparoscopic port site, amniocentesis needle tracts, episiotomy and Bartholins cyst excision sites. ${ }^{5}$

The classic symptoms of abdominal wall endometriosis are pain associated with a tender nodule or mass in the abdominal wall. Bleeding from superficial lesion may occur infrequently. The swelling is likely to increase in size during menstruation. The average time lag to develop symptoms of cutaneous endometriosis from the time of index surgery is 3.6 years. ${ }^{6}$ 
Physical examination reveals a tender discoloured swelling over and around the previous scar. Ultrasound examination can be done to check the plane of lesion and the associated pelvic endometriosis. The treatment of choice is wide local excision to achieve negative margins. If rectus muscle is involved it requires enbloc resection of myofascial elements. ${ }^{6}$

\section{METHODS}

This is a retrospective analysis of data collected from computer generated medical records of patients admitted with the diagnosis of endometriosis for a period of 5 years from 2009 to 2013 at a teaching hospital and a tertiary referral center, Christian Medical College and Hospital, Vellore, India. Among those women with diagnosis of abdominal wall endometriosis, the clinical presentation, management and pathological findings were studied. Detailed history was recorded with regards to previous surgery like caesarian section or hysterotomy. Symptoms of a mass or swelling over the scar site with associated pain and bleeding was recorded in all patients. All patients underwent wide local excision of scar endometriosis which was then confirmed on histological examination.

The frequency and percentages for each symptom was obtained for statistical analysis. The distribution of each symptom by the presence of endometriosis was given by frequencies and percentages. The chi-square test was done to find the association of each symptom and endometriosis. Each of those symptoms was also analyzed using penalized logistic regression as the study dealt with small number of subjects.

\section{RESULTS}

The total number of patients with endometriosis admitted for surgery was four hundred and ninety three of which 41 had abdominal wall endometriosis giving a prevalence rate of $8.3 \%$. $91 \%$ of women with abdominal wall endometriosis belonged to the reproductive age group with a mean age of $34.5 \pm 9.6$ years. 44 patients were multiparous. 32 had previous caesarean section, 2 had hysterotomy, 3 had hysterotomy. Remaining 8 were following appendectomy, puerperal sterilization and episiotomy.

Table 1: Sensitivity and specificity of the symptoms and index surgery.

\begin{tabular}{|lllllll|}
\hline Symptoms & Sensitivity $(\%)$ & Specificity $(\%)$ & PPV $(\%)$ & NPV $(\%)$ & LR+ & LR- \\
\hline Pain & 97.2 & 0 & 90.9 & 0 & 0.98 & \\
\hline Mass & 90.2 & 50 & 94.9 & 33.3 & 1.80 & 0.20 \\
\hline Bleeding & 2.4 & 75 & 50 & 7 & 0.10 & 1.30 \\
\hline Previous LSCS & 78 & 100 & 100 & 30.8 & & 0.22 \\
\hline Pain + mass + Previous LSCS & 71 & 100 & 100 & 25 & 0.29 \\
\hline
\end{tabular}

Table 2: Univariate and multivariable penalized logistic regression analysis.

\begin{tabular}{|lllllllll|}
\hline \multirow{2}{*}{ Symptoms } & \multicolumn{2}{l}{ Endometriosis by Clinical Diagnosis } & \multicolumn{2}{l}{ Multivariable Analysis } & \\
& Yes & \multicolumn{3}{l}{ OR } & 95\% CI & P value \\
& $\mathrm{n}$ & $\%$ & $\mathrm{n}$ & $\%$ & & & & \\
\hline Pain & 40 & 90.9 & 4 & 9.1 & 19.25 & 0.09 & 2622.74 & 0.208 \\
\hline Mass & 37 & 94.9 & 2 & 5.1 & 1.75 & 0.12 & 19.71 & 0.661 \\
\hline Bleeding & 1 & 50.0 & 1 & 50.0 & 0.01 & 0.00 & 5.73 & 0.295 \\
\hline Previous LSCS & 32 & 100 & 0 & 0 & 18.86 & 1.65 & 1594.94 & 0.016 \\
\hline
\end{tabular}

Swelling and excruciating pain at the scar site was reported in $86.6 \%(n=39)$. However, $2.2 \%$ of cases had swelling alone and $11 \%$ had pain alone as the presenting feature. Bleeding from the lesion associated with severe pain was reported in $4.3 \%$ of the patients. None of the patients had dyspareunia, dyschezia and chronic pelvic pain which are suggestive of pelvic endometriosis.

Pain, mass and Previous LSCS had sensitivity of $71 \%$ and specificity of $100 \%$ in the diagnosis of abdominal wall endometriosis. However $100 \%$ specificity is due to the small number of patients $(n=4)$. The likelihood ratio is 0.29 , indicating that even if there is no history of previous LSCS, with pain and mass, there is 0.29 times likelihood of endometriosis being positive (Table 1).

With previous LSCS, the odds of having abdominal wall endometriosis is 19 times (95\% CI 1.7-1595), compared to those women who did not have previous LSCS, with a $\mathrm{P}$ value of 0.016 , which is significant. With pain, the odds of having abdominal wall endometriosis is 19.25 times (95\% CI 0.09-2623), with a P value of 0.208 . However this is not significant (Table 2). 


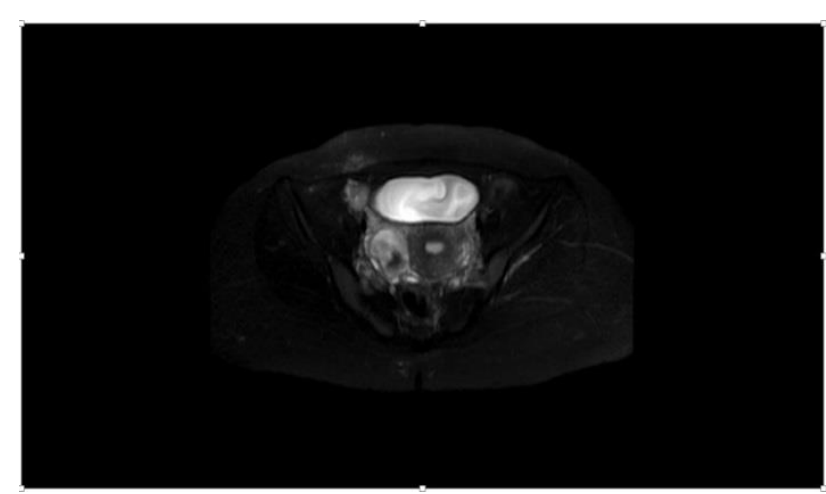

Figure 1a: MRI abdomen and pelvis.

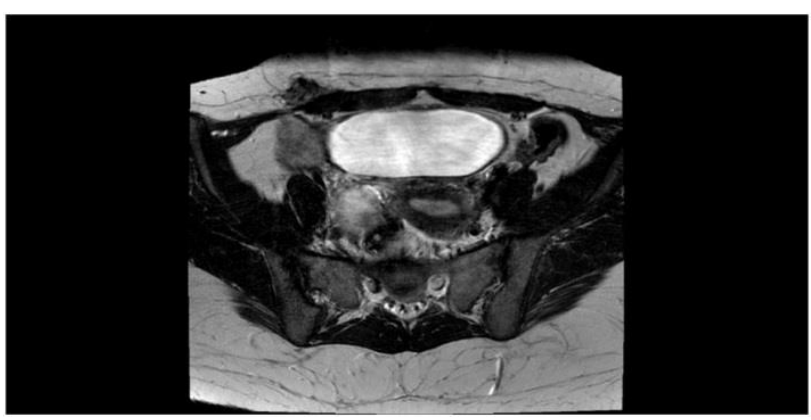

Figure 1b: T2 weighted high resolution image.

\section{DISCUSSION}

Abdominal wall endometriosis is defined as endometrial tissue within the abdominal wall, superficial to the peritoneum. There are currently no accepted classification systems for extra pelvic endometriosis. The classification proposed in 1989 classified extra genital endometriosis into Class I involving the intestinal tract, Class U involving the urinary tract, Class $\mathrm{L}$ involving all other sites including skin and nervous tissue. ${ }^{7}$ AWE falls into the category of Class L. The endometrial tissue grows invasively into the subcutaneous tissue and muscle. Due to its infiltrative tendency it gives rise to pronounced fibrotic adhesions which can be misinterpreted as a neoplastic tumor. Cutaneous endometriosis is a rare entity and develops at the site of previous abdominal operation or pelvic procedure. It is seen in $0.07-0.46 \%$ of cases after hysterotomy or caesarian section at the pfannensteil scar. ${ }^{8}$ Scar site endometriosis has been reported to occur in approximately $0.03 \%$ to $0.4 \%$ of women undergoing caesarean section. ${ }^{4,9}$ In this study the high prevalence of scar endometriosis, could be a study bias related to referred cases, seen in a higher center. All patients had undergone caesarian section at other hospital. In this study 32 had previous caesarian section, 2 had hysterotomy, 3 had hysterotomy. Remaining 8 were following appendectomy, puerperal sterilization and episiotomy. The average time lag to develop symptoms of cutaneous endometriosis from the time of index surgery is 3.6 years. $^{6}$ In this study, index surgery caesarian section was done less than 6 years prior to presentation.

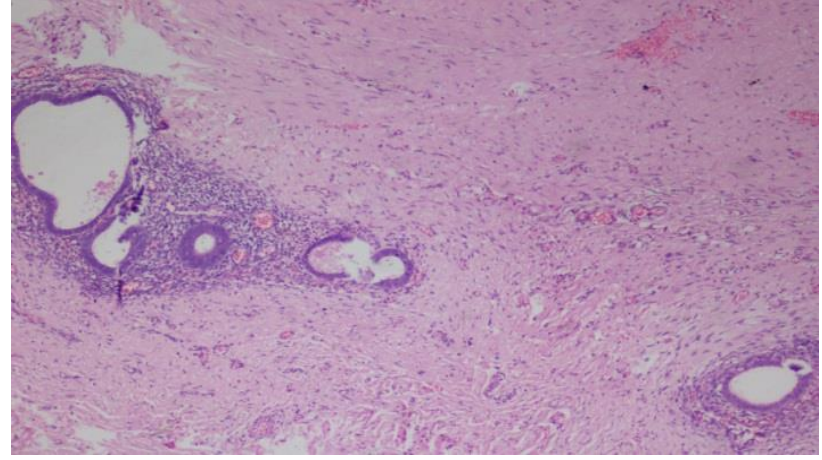

Figure 2a: Histopathological appearance of abdominal wall endometriosis, showing endometrial stroma and glands in fatty connective tissue (X 4).

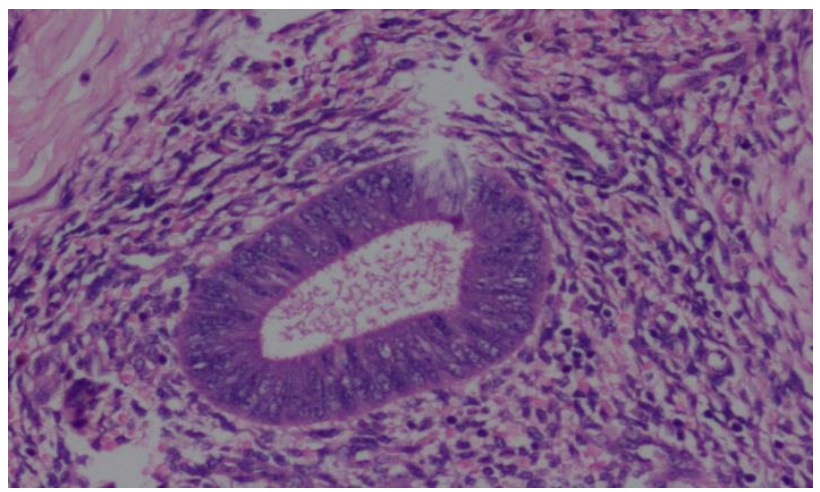

Figure 2b: Histopathological appearance of abdominal wall endometriosis, showing endometrial stroma and glands in fatty connective tissue (X 20).

Abdominal wall endometriosis, typically affects young women of reproductive age between 25 to 35 years. ${ }^{6}$ In this study $91 \%$ of women with abdominal wall endometriosis belonged to the reproductive age group with a mean age of $34.5 \pm 9.6$ years.

The main factor that predicted endometriosis was index surgery of previous LSCS. ${ }^{6}$ In this study, with previous LSCS the odds of having endometriosis was nearly 19 (95\% CI 1.7-1595) times as compared to those women who did not have previous LSCS $(p=0.016)$. This was the only factor that contributed to the presence of endometriosis.

According to the implantation theory of Sampson, during caesarian section, endometrial cells escape through the incision in the uterus and implant within the abdominal wound. ${ }^{10}$ According to Halbans theory of vascular dissemination, individual endometrial cells escape the uterus through the lymph vascular channels, gain access to the peripheral circulation and are carried to ectopic sites. ${ }^{11}$ A third theory involves metaplasia of cells, in the abdominal wall into endometrial tissue. ${ }^{12}$ At caesarian section, the incision made on the gravid uterus, supports mechanical transplantation theory and is believed that the endometrium is transplanted iatrogenically to the surgical scar. This supports the theory of direct implantation of 
endometrial cells on the abdominal wall. ${ }^{4}$ Abdominal wall endometriosis has been reported in port sites after laparoscopy. ${ }^{13}$ Caution during surgical procedures may reduce the incidence of AWE. Suturing the uterus with a different needle and removing the corpus luteum, reduces the possibility of the hormonal environment in formation of scar endometriosis, ${ }^{14}$ but these techniques were not tested rigorously.

The classical symptom seen in majority of cases is palpable erythematous skin nodule or swelling over the scar associated with intermittent excruciating pain, tenderness, and enlargement of the mass during menstruation. Cyclical abdominal pain is reported in $57 \%$ of cases, while $96 \%$ had abdominal mass. ${ }^{6}$ In this study $86.6 \%$ of women had a palpable mass with associated pain, $11 \%$ had only pain, $2.2 \%$ of cases had swelling alone at the scar site. However, $4.4 \%$ had pain and bleeding from the scar site. Physical examination should focus on determining the presence of a facial defect. The main differential considered with a soft tissue mass would be a desmoid tumor, haematoma, granuloma, ventral hernia, lipoma, sebaceous cyst, haemangiomas or lymphangioma. ${ }^{15,16}$ In larger lesions the imaging report may assist with surgical planning especially when an abdominal wall reconstruction is anticipated. ${ }^{17}$ Ultrasound shows an ill-defined hyperechoic lesion in the anterior abdominal wall at the site of the previous scar. ${ }^{18}$ In this study the ultrasound was done in 18 patients to look for associated pelvic endometriosis of which evidence of scar endometriosis was reported in 14 patients. On CT, AWE usually appears as a circumscribed heterogeneous mass with no capsule enhanced by contrast and may show hemorrhages. ${ }^{19}$ Due to high viscosity and high protein and iron content, the MRI appearance shows hyperintensity on T1-weighted images and hypointensity on T2 weighted images, ${ }^{20}$ as shown in the figure. Fine needle aspiration biopsy increased the risk of recurrence. ${ }^{6}$

The treatment of choice for abdominal wall endometriosis is the wide local excision including the adjacent fascia to achieve negative margins. ${ }^{21}$ In cases where abdominal wall endometriosis is incorporated into the musculature of abdominal wall; it requires enbloc resection of involved myofascial elements. Histological examination reveals, foci of endometriosis composed of endometrial glands and stroma, hemosiderin pigment, fibrosis, chronic inflammation, and old hemorrhage and the presence of adipose and fibrous tissue. ${ }^{22}$ Pathological diagnosis was confirmed in $91 \%(n=41)$ of patients, while in 4 cases the scar was reported as suture granuloma. Malignant transformation is rare, however clear cell adenocarcinoma has been reported. ${ }^{23}$ Local recurrence can occur if the margins are not adequately resected. Recurrence rate is $4.3 \%$ with negative surgical margins. ${ }^{6}$

The hormonal management with progestogens and gonadotropin releasing hormone analogues has short term success in alleviation of symptoms but recurrence is common after cessation of treatment. However it can be reserved for patients who have concomitant pelvic endometriosis. $^{15}$

The diagnostic triad studied was swelling and pain over the scar site with index surgery of caesarean section. Previous LSCS along with pain and swelling was $71 \%$ sensitive and $100 \%$ specific $(n=4)$, in diagnosing abdominal wall endometriosis. The likelihood ratio is 0.29 , indicating that even if there is no history of previous LSCS, with associated pain and mass, there is 0.29 times likelihood of endometriosis being positive.

\section{CONCLUSIONS}

In conclusion, abdominal wall endometriosis can be diagnosed on the basis of painful swelling during menstruation over the scar site with the index surgery of previous LSCS. Index surgery of Previous LSCS along with pain and swelling had a sensitivity of $71 \%$ and specificity of $100 \%$ in diagnosing abdominal wall endometriosis. The odds of having endometriosis in patients with previous LSCS was nearly 19 (95\% CI 1.71595) times as compared to those women who did not have previous LSCS $(\mathrm{P}=0.016)$. Considering a high incidence of abdominal wall endometriosis following a caesarean section, proper precautions should be taken during caesarean section or hysterotomy to prevent the iatrogenic inoculation of endometrial tissue into the incision.

\section{Funding: No funding sources \\ Conflict of interest: None declared \\ Ethical approval: Not required}

\section{REFERENCES}

1. Vigano P, Parazzini F, Somigliana E. Endometriosis: epidemiology and aetiological factors. Best Pract Res Clin Obstet Gynecol. 2004;18:177-200.

2. Olive DL, Schwartz LB. Endometriosis. N Engl J Med 1993;328:1759-69.

3. Sonavane SK, Kantawala KP, Menias CO. Beyond the boundaries-endometriosis: typical and atypical locations. Curr Probl Diagn Radiol. 2011;40(6):21932.

4. Khoo JJ. Scar endometriosis presenting as an acute abdomen: A case report. Aust NZ J Obstet Gynaecol. 2003;43(2):164-5.

5. Jan-Hein J. Hensen, Adriaan C, Van Breda Vriesman, Julien B. C. M, Puylaert Abdominal Wall Endometriosis: Clinical Presentation and Imaging Features with Emphasis on Sonography. 2006;186(3):616-20.

6. Horton JD, Dezee KJ, Ahnfeldt EP, Wagner M. Abdominal wall endometriosis: a surgeon's perspective and review of 445 cases. Am J Surg 2008;196(2):207-12. 
7. Markham SM, Carpenter SE, Rock JA. Extrapelvic endometriosis. Obstet Gynecol Clin North Am. 1989;16:193-219.

8. Bektas H, Bilsel Y, Sari YS, Ersoz F, Koc O, Deniz $\mathrm{M}$, et al. Abdominal wall endometrioma: A 10 -year experience and brief review of the literature. J Surg Res. 2010;164(1):e77-e81.

9. Singh KK, Lessells AM, Adam DJ, Jordan C, Miles WF, Macintyre IM, et al. Presentation of endometriosis to general surgeons: a 10-year experience. Br J Surg. 1995;82(10):1349-51.

10. Vinatier D, Orazi G, Cosson M, Dufour P. Theories of endometriosis. European Journal of Obstetrics Gynecology and Reproductive Biology. 2001;96(1):21-34.

11. Halban J. Hysteroadenosis metaplastica. Wien Klin Wochenschr. 1924;37:1205-6.

12. Gruenwald P. Origin of endometriosis from the mesenchyme of the celomic walls. American Journal of Obstetrics and Gynecology. 1942;44(3):470-474.

13. Arif Emre, Sami Akbulut, Mehmet Yilmaz, Zehra Bozdag. Laparoscopic Trocar Port Site Endometriosis: A Case Report and Brief Literature Review. Int Surg. 2012;97(2):135-9.

14. Sinha A, Sinha S: Endometriosis of the abdominal scar. J Obstet Gynaecol. 1977;27:457-8.

15. Wolf Y, Haddad R, Werbin N, Skornick Y, Kaplan O. Endometriosis in abdominal scars: a diagnostic pitfall. Am Surg 1996;62:1042-4.

16. Lauren Stein, Khaled M, Elsayes, Nicolaus WagnerBartak. Subcutaneous abdominal wall masses: Radiological reasoning. AJR:198,2012.
17. Hensen JH, Van Breda Vriesman AC, Puylaert JB. Abdominal wall endometriosis: clinical presentation and imaging features with emphasis on sonography. AJR Am J Roentgenol. 2006;186(3):616-20.

18. Amato M, Levitt R. Abdominal wall endometrioma: CT findings. J Comput Assist Tomogr. 1984;8:121314.

19. Patterson GK, Winburn GB. Abdominal wall endometriomas; report of eight cases. Am Surg. 1999;65(1);36-9.

20. Bennett GL, Slywotzky CM, Cantera M, Hecht EM. Unusual manifestations and complications of endometriosis: spectrum of imaging findings. AJR 2010; 194:S83;WS34-WS46.

21. Francica G, Scarano F, Scotti L, Angelone G, Giardiello C. Endometriomas in the region of a scar from Cesarean section: sonographic appearance and clinical presentation vary with the size of the lesion. J Clin Ultrasound. 2009;37(4):215-20.

22. C. P. Crum, "The female genital tract," in Robbins Pathologic Basis of Disease, R. S. Cotran, V. Kumar, and V. Collins, Eds., Saunders, Philadelphia, Pa, USA, 6th edition, 1999.

23. Sergent F, Baron M, Le Cornec JB, et al: Malignant transformation of abdominal wall endometriosis; A new case report. J Gynecol Obstet Biol Reprod. 2006;35:186-90.

Cite this article as: Lakshmi L, Londhe V, Tejovathy K, Varghese L, Visali J, Kekre AN. Abdominal wall endometriosis: accuracy of the diagnostic triad. Int J Reprod Contracept Obstet Gynecol 2015;4:1417-21. 